\title{
LEITURA, ESCOLA E O COMPROMISSO DO PROFESSOR: ENTRE PREOCUPAÇÕES E PROVOCAÇÕES
}

\author{
LA LECTURA, LA ESCUELA Y EL COMPROMISO DEL PROFESOR: ENTRE \\ LAS PREOCUPACIONES Y LAS PROVOCACIONES
}

\author{
READING, SCHOOL AND TEACHER COMMITMENT: BETWEEN CONCERNS \\ AND PROVOCATIONS
}

\author{
Cícera Maria dos SANTOS ${ }^{1}$ \\ Cloves Santos de MORAES ${ }^{2}$ \\ Célia de Jesus Silva MAGALHÃES ${ }^{3}$
}

RESUMO: Este trabalho discute a problemática que envolve o hábito da leitura na Educação Básica. Tem como objetivo discutir questões relacionadas às dificuldades de leitura bem como o papel da escola e dos professores na minimização do problema em questão. Com base em pesquisas e ensaios relevantes sobre o tema, explicita o tema a partir do conceito de leitura e sua utilização no cotidiano do aluno. Faz referência as estratégias de ensino da leitura como condição essencial ao desenvolvimento da competência leitora. Enfatiza o papel da escola enquanto instituição responsável formalmente e parcialmente pelo aprendizado cognitivo do aluno nas diferentes áreas do conhecimento, primando pela proficiência leitora. Apresenta como saída ao problema detectado o estímulo por parte da escola e desempenho de seus profissionais, em criar situações em que o aluno aprecie a importância da leitura, bem como mostrar a importância da formação contínua dos professores, a reflexão e avaliação de suas práticas pedagógicas.

PALAVRAS-CHAVE: Leitura. Aprendizagem. Dificuldades de leitura.

RESUMEN: Este trabajo discute la problemática que implica el hábito de la lectura en la educación básica. Su objetivo es debatir cuestiones relacionadas con las dificultades de la lectura y el papel de la escuela y de los docentes en la minimización del problema en cuestión. Basándose en investigaciones y ensayos relevantes sobre el tema, explica el tema del concepto de la lectura y su uso en la vida cotidiana del estudiante. Se refiere a las estrategias didácticas de la lectura como condición esencial para el desarrollo de la competencia lectora. Enfatiza el papel de la escuela como una institución responsable formal y parcialmente por el aprendizaje cognitivo del alumno en las diferentes áreas del conocimiento, primando por el dominio de los lectores. Se

${ }^{1}$ Graduada em Letras pela Universidade Regional do Cariri (URCA). E-mail: mari_acicera@hotmail.com

${ }^{2}$ Graduando em Letras pela Universidade Regional do Cariri (URCA) - VI semestre. Tem experiência como professor na educação básica. Atualmente, é bolsista PIBIC/URCA/FUNCAP, desde 2016, vinculado ao projeto de Iniciação Científica: Fios e desafios na formação pedagógica dos licenciandos do curso de letras da Universidade Regional do Cariri (URCA). E-mail: clovessantos0@ gmail.com

${ }^{3}$ Mestre em Educação pela Universidade Federal da Paraíba (2011). Atualmente é professor substituto da Universidade Regional do Cariri e diretora acadêmica - Unidade Missão Velha da Universidade Regional do Cariri. E-mail: celia.magalhaes@urca.br

RPGE- Revista on line de Política e Gestão Educacional, v.21, n.1, p. 227-247, 2017 
presenta como una salida al problema detectado el estímulo de la escuela y el desempeño de sus profesionales, en la creación de situaciones en las que el alumno aprecie la importancia de la lectura, además de mostrar la importancia de la formación continua de los docentes, la reflexión y evaluación de sus prácticas pedagógicas.

PALABRAS CLAVES: Lectura. Aprendizaje. Dificultades para leer.

ABSTRACT: This paper discusses the problems involving the habit of reading in basic education. Aims to discuss issues related to reading difficulties as well as the role of the school and teachers on minimization of the problem in question. Based on research and relevant trials on the subject, explains the theme from the concept of reading and your everyday use of the student. References reading education strategies as an essential condition for the development of competence reader. Emphasizes the role of the school as an institution responsible for formally and partly by the student's cognitive learning in the different areas of knowledge, excelling in reading proficiency. Presents as output to the problem detected by the stimulation and school performance of its professionals, create situations where students appreciate the importance of reading, as well as showing the importance of continuous training of teachers, the reflection and evaluation of their pedagogical practices.

KEYWORDS: Reading. Learning. Reading difficulties.

\section{Introdução}

A leitura permeia o cotidiano das pessoas nas mais variadas atividades, desde a simples tarefa de tomar um ônibus, como em situações mais complexas. Nesta perspectiva, este trabalho visa sublinhar aspectos relacionados às dificuldades de leitura dos alunos na educação básica, realçando, entre outros elementos, as dificuldades encontradas pelos alunos para ler com significação, para conseguir extrair informações e compreender a mensagem do texto lido.

A problemática da educação relativa à aprendizagem da leitura e o baixo índice apresentado quanto ao seu domínio por parte dos alunos que ingressam no Ensino Médio constituem questões que inquietam e angustiam profundamente todos os envolvidos no sistema de ensino, seja ele público ou privado.

Verifica-se, então, a necessidade de formarmos alunos leitores e produtores de texto, motivo pelo qual desenvolvemos este trabalho sobre a leitura, sua importância e a forma de ser trabalhada, em face à inquietação de colegas que destacam a difícil tarefa de conseguir com que os alunos aprendam a ler, desenvolvam o hábito da leitura e se tornem capazes de produzirem e compreenderem textos significativos. Isso não é um problema detectado somente nas disciplinas da área de Linguagem e Códigos, mas sim, 
um problema que perpassa todas as áreas do conhecimento e que atinge a maioria dos alunos da educação básica.

A pesquisa aqui desenvolvida, portanto, apresenta uma discussão sobre a importância dos processos que envolvem a leitura na educação básica, visto que este tema se apresenta como uma das maiores, senão, a principal missão da escola: despertar na população discente o hábito da leitura. Para isso, foi necessário recorrer a uma extensa pesquisa bibliográfica a partir das leituras de Koch (2010), Venturelli (1995), Cagliari (1997), Freire (1998), Solé (1998), Costa (1999), Grossi (2002) e Batista (2006), dentre outros. As ideias apresentadas aqui só tendem a ampliar ainda mais os horizontes no mundo maravilhoso da leitura.

\section{Conceitos de leitura}

Muitas são as tentativas de se definir o processo de leitura. De acordo com Freire (1998, p.2), "ler é ser capaz de transformar uma mensagem escrita numa mensagem sonora segundo certas leis precisas. É compreender o sentido da mensagem escrita". Deste modo, Freire compreende a leitura não apenas como decodificação, mas também como compreensão, pois, segundo o autor, a leitura do mundo precede a leitura da palavra.

De acordo com Batista (2006, p.40): “A leitura é uma atividade que depende de processamento individual, mas se insere num contexto social e envolve disposições atitudinais, capacidades relativas à decifração do código escrito e capacidades relativas à produção de sentido". Podemos perceber que a leitura depende tanto do indivíduo que a exerce, envolvendo, assim, muitas questões relativas ao leitor, como suas capacidades e disposições para que esta possa vir a fazer sentido para o mesmo, como do contexto social. Conforme afirma ainda Batista et al (2006):

A leitura é uma prática social que envolve atitudes gestos e habilidades que incorporam ao leitor em suas três fases, antes, durante e após a leitura. Podemos afirmar ainda que, quando um leitor realiza uma leitura, o seu conhecimento prévio, ou seja, suas leituras anteriores servirão de suporte para as futuras leituras (BATISTA et al, 2006, p.40) 
Já Cagliari (1997) apresenta, digamos assim, um conceito de leitura mais amplo que aquele dos dois últimos autores.

O termo leitura tem muitos sentidos, aplicando-se a muitas áreas e a habilidades diferentes, como ler o mundo, ler um quadro, fazer uma leitura de um fato ou de um lugar, etc. Na escola, o significado mais usual e mais importante é saber interpretar. A leitura é algo que traz uma mensagem que precisa ser entendida. Para se chegar a essa habilidade, é preciso percorrer um longo caminho de estudos e praticar o ato de ler inúmeras vezes, em inúmeras circunstâncias e com inúmeros tipos de material escrito. Esse é o ponto de chegada (CAGLIARI, 1997, p.35).

O autor afirma que atitudes como gostar de ler e interessar-se pela leitura e pelos livros são construídas, ao longo da vida em vários espaços de convivência em que a leitura e a escrita se apresentam. Mas é, sobretudo, na escola que este gosto deve e precisa ser incentivado e vivido constantemente porque julga que lá seja o lugar privilegiado, por assim dizer, para o desenvolvimento da habilidade de interpretar. É muito importante que o aluno perceba a leitura como algo prazeroso e necessário e que tenha naqueles que estão ao seu redor um exemplo.

A leitura é um processo diante do qual o homem compreende a linguagem escrita, intervindo no texto, mobilizando suas ideias, expectativas e conhecimentos prévios. Para ler é preciso, simultaneamente, manejar de forma hábil as habilidades de decodificação e buscar novos objetivos no texto. Devemos envolver-nos num processo de previsão e inferência contínua, que deve estar apoiado na informação proporcionada pelo texto e em nossa bagagem cultural.

O conceito de leitura que é fundamentado nos estudos conhecidos genericamente como linguística pragmática, de acordo com Koch (2010, p. 13), trata "de manifestações linguísticas produzidas por indivíduos concretos em situações concretas, sob determinadas condições de produção. Nesta visão ler seria igual a construir sentidos". Assim, na construção de sentido, a leitura é o resultado da interação entre informações significativas e contextualizadas, de acordo com seu conhecimento de mundo. Desse modo, o ato de ler é uma ação ativa, de participação e não de um ato passivo de informações.

O conceito de leitura dado por Cagliari (1997) apresenta-se de forma ampla e bastante satisfatória, pois apresenta um leque de informações que caracterizam a leitura, enfatizando fatos primordiais como compreensão de vários tipos de leitura em diversos 
âmbitos e também como resultado de um longo processo, que representam o enfoque que desejamos dar a esta pesquisa.

\section{A leitura na escola}

Um dos múltiplos desafios a ser enfrentado pela escola é o de fazer com que os alunos desenvolvam com proficiência a sua compreensão leitora. $\mathrm{O}$ aluno pode ler corretamente, decodificar e, no entanto, não atribuir sentidos autorizados, adequados aos textos. Desse modo, julgamos necessário, óbvia e urgente a aquisição da leitura pelos indivíduos.

Assim, julgamos que muitos dos problemas que ocorrem na dimensão quantitativa (mais ou menos leitura) e na dimensão das condições qualitativa (boa ou má leitura) do processo, dependem das condições escolares concretas para a sua produção, pois com base no educador Paulo Freire, acreditamos que o caráter livresco do ensino e as formas autoritárias através dos quais os livros são apresentados em sala de aula tendem a contribuir com uma formação improdutiva para os estudantes, gerando a falsa crença de que tudo que está escrito ou impresso é necessariamente verdadeiro. Freire (1998) chama isto de "educação bancária" - o professor é para o aluno um conjunto de informações apenas para encher a cabeça do mesmo. Daí a passividade, o amortecimento da crítica e da criatividade, o consumo mecânico e não significativo das ideias propostas nos textos.

Logo, quando ocorre o inverso, ou seja, quando o aluno é movido por curiosidade, pelo desejo de crescer, ele se renova constantemente, tornando-se cada dia mais apto a estar no mundo, capaz de compreender aquilo que se ouve e vê. Tornandose um ser autônomo, crítico e construtivo.

Ler, é uma necessidade de todas as pessoas, relaciona-se à capacidade de eleger, escolher, decifrar, conhecer e interpretar informações, conhecimentos e saberes registrados segundo as normas da cultura letrada.

Nessa perspectiva, o bom leitor é aquele que vai além da decifração de um termo para captar ideias, conceitos e teorias, visando à ampliação dos horizontes culturais próprios e do seu entorno humano.

Ao ler, inicialmente, o leitor é desafiado a identificar o sentido das letras e palavras, dos parágrafos e capítulos, os chamados "símbolos gráficos textuais" que se apresentam repletos de noções, ideias, conceitos, opiniões, teses, leis e teorias relativas 
ao objeto a que se refere e investiga. É nessa etapa que os dicionários e assemelhados são imprescindíveis.

Já afirmamos com base em Cagliari (1997) que a escola, é um importante veículo na promoção da interação do aluno com o texto, daí a responsabilidade da escola de formar leitores competentes, pois:

O leitor competente, além de decifrar um código, assimilar estruturas gramaticais complexas e aprimorar a linguagem, consegue se expressar, aprende a dizer o que quer e é crítico. Contribui com o texto, sabe olhar para o contexto e percebe a realidade a sua volta. E consegue reconhecer e ler diferentes tipos de texto. Sim, porque esse leitor pode até sentir dificuldades ao deparar com um texto mais complexo - as grandes obras literárias - , mas ele não sente medo ou tem preconceito (VENTURELLI, 1995, p. 178).

Percebemos que um leitor competente é alguém que compreende o que lê; que aprende a ler também o que não está escrito, identificando elementos implícitos; que estabeleça relações entre o texto que lê e outros textos já lidos; que sabe que vários sentidos podem ser atribuídos a um texto; que consegue justificar e validar sua leitura a partir da localização de elementos discursivos que o permitam fazê-lo.

Numa sociedade cada vez mais apoiada na obtenção rápida de informação, os maus leitores são confrontados com grandes dificuldades - falta de compreensão da informação que exige recurso a conhecimentos exteriores ao texto e deficiente análise do conteúdo do texto, o que vai comprometer o acesso à informação e à construção do conhecimento. E tudo isto é uma bola de neve. Da próxima vez em que for necessário mobilizar e transferir conhecimentos para compreender outro texto sobre a mesma temática, estará, de novo, em desvantagem em relação aos leitores fluentes.

O que constatamos é que, com tanta informação disponível, nem todos conseguem acessá-la do mesmo modo, nem tão pouco usufruir dos mesmos benefícios. $\mathrm{E}$ isto faz toda a diferença. Aprende-se a ler por obrigação enquanto se frequenta a Escola, mas não se cria o prazer de folhear um livro e lê-lo por gosto, quer para consolidar as aprendizagens, quer para adquirir novos conhecimentos. Ler melhor significa também falar e escrever melhor nas mais diversas situações de comunicação o que implica ser cidadão de pleno direito, crítico e capaz de construir sentidos e de identificar as contradições e manipulações que as mensagens podem conter.

É através da leitura que somos confrontados com ideias e mundos diferenciados que enriquecem o nosso patrimônio cultural e nos ajudam a refletir e a consolidar opiniões. E é igualmente no ato de ler que, por vezes, encontramos um espaço lúdico e 
de evasão, que abre as portas a uma dimensão tão importante, no homem, como é a da imaginação e criatividade.

\section{Estratégias de leitura}

O professor exerce um papel de grande importância ao propiciar não somente a aprendizagem em leitura, mas também ao propor modelos técnicos e procedimentos que proporcionem a compreensão leitora. O processo de ensinar seria uma forma de possibilitar ao estudante desenvolver estruturas conceituais e procedimentais que implementem seu desempenho.

De acordo com Solé (1998):

É preciso que o ensino da leitura ocorra seguindo um ritmo, passando por etapas que o ajude a aquisição deste aprendizado ressaltando-se o uso de estratégias de leitura para cada uma dessas etapas: Antes: predições iniciais sobre o texto e objetivos da leitura; Durante: levantamento de questões de controle e compreensão e Depois: construção da ideia principal e resumo (SOLÉ, 1998, p. 14-21).

Outro ponto positivo com relação ao uso das estratégias de leitura, é que também auxiliam no estudo, favorecendo a obtenção de um nível de compreensão melhor. É importante salientar que estas exigem participação ativa do leitor, podendo ser aplicadas a qualquer tipo de texto e em qualquer momento da leitura, com ou sem ajuda externa. Não podemos esquecer que o ensino de estratégias de leitura abre novas perspectivas para uma potencialização da leitura, possibilitando aos alunos ultrapassarem dificuldades pessoais de forma a conseguir obter um maior sucesso escolar. Essas podem e devem ser ensinadas desde as séries iniciais do ensino fundamental.

Dentre as estratégias de leitura que os professores podem ensinar está a de focar a atenção dos alunos nas ideias principais, perguntar questões sobre seu entendimento para ajudar a monitorar sua compreensão; relacionar o conhecimento prévio dos alunos com nova informação; questionar e designar feedback para ajudar os alunos a aplicarem técnicas e estratégias de estudo apropriadas; treinar os alunos a usarem essas estratégias e técnicas de maneira mais efetiva; utilizar reforços positivos verbais e de escrita com os alunos que apresentam baixa compreensão; propor questões 
aos alunos para ajudar a reconhecer a contradição entre o que ele realmente conhece e o que ele acredita conhecer, mas não conhece; além de considerarem a variedade dos textos estruturados na preparação dos textos para alunos e plano de aula.

Podemos citar um exemplo de um modelo de instrução desenvolvido por Costa (1999), que consiste em 4 etapas:

Na primeira - $O$ quê - o professor informa os tipos de estratégia de leitura que podem ser usadas. Na segunda etapa - Por quê - o professor diz ao aluno porquê a estratégia de compreensão é importante e como a aquisição pode ajudar a tornar-se um leitor melhor. A terceira etapa Como - envolve a instrução direta da estratégia. Ela pode envolver explanação verbal, modelo ou pensar em voz alta. E a quarta etapa Quando - envolve a comunicação de quando a estratégia deve ser usada ou não, e como evoluir e corrigir seu uso (COSTA, 1999, p. 65-66).

Desse modo, todas as pesquisas elencadas acima sobre o ensino das estratégias de leitura têm constatado que essa é uma ação eficaz não somente para alunos com dificuldade em compreensão, mas também para os leitores hábeis. Esses são os recursos que buscamos para fundamentar esta pesquisa que investigou tais problemas de leitura e ser mais um aliado na busca da melhoria da qualidade de ensino e o crescimento do aluno tão carente e deficiente.

Solé (1998), defende um ensino de leitura no qual se aprende a ler lendo, onde o aprendiz deve estar em contato com todos os tipos de textos sociais dos quais precisa e se utiliza dele no cotidiano. Segundo a autora, ao longo do ano escolar, a escola teima em dar uma ênfase muito maior à escrita do que à leitura. $\mathrm{O}$ aluno é muito mais exigido em relação a escrita do que em relação a leitura. Acredita-se que a escola prioriza a avaliação da escrita, pois é mais fácil apontar erros e acertos desta, enquanto que a avaliação de leitura, o professor não sabe muito bem o que o aluno faz quando lê, principalmente quando lê silenciosamente.

Desse modo, para a autora, é preciso repensar os procedimentos relacionados à leitura e à escrita na escola, dando um lugar de maior destaque e prestígio à leitura desde o início do processo de escolarização, pois, segundo Solé (1998) uma criança que aprende a ler adquire fluência no aprendizado do segundo ano. Um aluno que não lê aprenderá o resto com dificuldade e pode passar a ter uma relação delicada com a escrita, não entendendo muito bem o que esta é nem como funciona. 


\section{O papel da escola e o compromisso do professor}

Na era da informática é preciso que a escola vá além das regras convencionais da leitura e da escrita, tornando-os alunos aptos para a cultura letrada. É preciso formar essa população discente para acompanhar as novas exigências no que diz respeito à leitura e à escrita a partir da utilização das novas tecnologias da comunicação, como computador, internet, etc. Grossi explícita que:

A escola não está cumprindo com as suas finalidades. Ou ela se reinventa ou desempenhará apenas um papel secundário para a construção de uma sociedade mais feliz e mais materna, onde haja a sua finalidade básica de produzir o acesso ao mundo letrado através da alfabetização (Grossi, 2002, p. 15).

Diante deste contexto tecnológico, constituído por inúmeras inovações, percebemos a banalização das informações que nos chegam hoje. Anos atrás, as informações chegavam aos poucos e era possível assimilá-las, analisá-las e até comentálas. Com o avanço acelerado dos meios de comunicação como a televisão, rádio, os vídeos, DVDs e a internet, que a cada segundo nos trazem uma infinidade de informações, o papel da escola e a função do professor e do aluno têm se modificado de forma incontestável.

Diante dessa concepção o professor precisa assumir uma nova postura que lhe permita orientar o aluno sobre como colher informações, como organizá-las mentalmente, como definir sua importância e principalmente como transformá-la em conhecimento.

Considerando a essência destas mudanças os docentes necessitam fazer uso em todas as oportunidades das aprendizagens por compreensão, eliminando atividades que conduzam à aprendizagem mecânica. No ensino, não basta discutir e teorizar o valor da leitura. É preciso construir e levar na prática para que a leitura venha a ser cada vez mais sedimentada na vida do educando.

Sabemos que nunca paramos de aprender a ler e escrever, que essa aprendizagem é contínua. Nesse contexto, Grossi (2002) sustenta que:

É verdade que, de certa forma a aprendizagem da língua materna, quer escrita, quer oral, é um processo permanente, nunca interrompido. Entretanto, é preciso diferenciar um processo de aquisição da língua oral e escrita de processo de desenvolvimento da 
língua oral e escrita, este último, sem dúvida, nunca se interrompe (GROSSI, 2002, p. 149).

De acordo com as experiências vivenciadas a partir do Ensino Médio, a leitura é um dos meios mais importantes utilizados pela escola para atingir novas aprendizagens. Isto não significa que não se considere mais necessário insistir no ensino da leitura. De fato, durante todas as etapas do processo de escolarização, seja no nível infantil, fundamental e também no médio, deve-se continuar reservando um tempo para a leitura, geralmente na parte de língua portuguesa e suas literaturas.

Vemos que tais procedimentos são fundamentais para o desenvolvimento de habilidades de leitura. Mas vale salientar que tais procedimentos precisam ser trabalhados desde o ensino fundamental para que ao longo do Ensino Médio possam ser amadurecidos, senão as deficiências estarão cada vez mais evidentes, deixando nossos níveis de leitura no mais baixo patamar.

\section{Considerações finais}

Ao longo deste trabalho investigamos alguns aspectos relacionados à compreensão leitora na busca de resultados significativos acerca dos processos envolvidos.

Salientamos que não é só o professor o responsável por todas essas deficiências existentes no processo ensino-aprendizagem da leitura, mas um conjunto de fatores de ordem, biológicas, pedagógicas, sócio-culturais, familiares, cognitivas e também de um sistema escolar voltado principalmente para a quantidade e não para a qualidade.

Nesta perspectiva, faz-se necessário que a escola, ao detectar tais dificuldades, busque, de alguma forma, intervir para tentar minimizar os grandes problemas relacionados a leitura. Para que isso tenha eficácia precisa-se muito, de uma escola que tenha uma parceria com a família e uma congregação de professores que busca e acredita que pode mudar os rumos da educação deste país e que, acima de tudo, acredita que esta mudança é possível e que cada um é responsável por esses rumos.

Ao concluirmos este trabalho percebemos que apresentamos muitas limitações por tratar-se de um trabalho menos abrangente onde muitos aspectos foram deixados de lado. Mas é importante salientar que este serve de parâmetro para que novos trabalhos 
neste sentido possam vir a ser feitos na tentativa de buscar novos focos na forma de ensino e estudo da leitura, ou qualquer um outro aspecto referente à Língua Portuguesa.

\section{Referências}

BATISTA, Antonio Augusto et. al. Capacidades linguísticas da Alfabetização e a Avaliação. Coleção: Pró-Letramento. Brasília: MEC. Secretaria de Educação Básica. Secretaria de Educação a Distância. Universidade federal de Minas Gerais, 2006.

CAGLIARI, L. C. Alfabetização e Linguística. São Paulo: Scipione, 1997.

COSTA, M. da G. Val. Redação e textualidade. São Paulo: Martins Fontes, 1999.

FREIRE: Paulo, A importância do ato de ler: em três artigos que se completam. São Paulo: Cortez, 1998.

GROSSI, Esther Pillar. Democracia: Sociedade onde todos aprendem. Porto Alegre, 2002.

KOCH, Ingedore Villaça. A inter-ação pela linguagem. 10. ed. São Paulo: Contexto, 2010

SOLÉ, Isabel . Estratégias de Leitura. Porto Alegre: Artmed, 1998.

VENTURELLI, Paulo César. Leitura: paixão do conhecimento. Revista Letras, n. 44, Curitiba: UFPR, p. 175-182. 1995.

\section{Como citar este artigo:}

SANTOS, Cícera Maria dos.; MORAES, Cloves Santos de.; MAGALHÃES, Célia de Jesus Silva. Leitura, escola e o compromisso do professor: entre preocupações e provocações. Revista on line de Política e Gestão Educacional, Araraquara, v.21, n.1, p. 248-258, 2017. Disponível em: <http://dx.doi.org/10.22633/rpge.v21.n.1.2017.9731>. ISSN: 1519-9029.

Submetido em: 18/04/2017

Aprovado em: 20/04/2017 